\title{
Prof. R. Robert Wenner
}

Mit dem Tode von Prof. Robert Wenner hat die Schweizerische Gynäkologie einen ihrer markantesten und wohl auch einen ihrer beliebtesten Vertreter verloren. Er verstarb am 27. April 1979 in seinem 70. Altersjahr für alle überraschend und scheinbar aus völliger Gesundheit heraus. Seine Frau, an der er sehr hing, war ihm im Tod 6 Monate vorausge-gangen.

Robert Wenner war seiner Erziehung, Ausbildung und Mentalität nach Europäer. In Neapel geboren, Sohn eines deutschschweizerischen Vaters und einer „Mère vaudoise”, stu-dierte er Medizin in Rom und Zurich. Er spracht perfekt Deutsch, Italíenisch, Französisch und besass in alien drei Sprachgebieten - Italien, Deutschland, Frankreich undderSchweiz -zahlreiche Freunde. Den Franzosen und der Französischen Gynäkologie war er aber immer besonders zugetan. Robert Wenner kam 1935, im Alter von 26 Jahren, ans Frauenspital Basel, wo er rasch Karriere machte: 1938 Erster Oberarzt, 1942 Habilitation, 1953 ausserordentlicher Professor. Nach einigen Jahren Privatpraxis in Basel bekleidete er 1962-1974 das Amt eines Chefarztes der Frauenklinik Liestal. Unter seiner Leitung erfreute sich diese Klinik bald internationaler Anerkennung. Allen Teilnehmern werden die Liestaler Fortbildungskurse für Frauenärzte und praktische Ärzte, die ganz von der Person Wenner geprägt waren, in bester Erinnerung bleiben. Nach seiner Pensionierung stellte er sein Organisationstalent und seine Arbeitskraft der Schweizerischen und der Baslerischen Krebsliga und vor allem der Schweizerischen Akade-mie Medizinischer Wissenschaften zur Verfügung, deren langjähriger Sekretär er war und deren nächster Präsident er hätte werden sollen.

Prof. Wenner hat mitgeholfen, die Schweizerische Gynäkologie nach dem Krieg im Ausland bekanntzumachen. Aufgrund seiner wissenschaftlichen Arbeiten und seiner inter-nationalen Verbindungen bekam er zahlreiche Einladungen zu Kongressreferaten in Deutschland, Italien, Frankreich und der Schweiz, in denen er seine Forschungsergebnisse vor allem auf dem Gebiet der gynäkologischen Endokrinologie und der Familienplanung bekannt-machte.

Die Anerkennung blieb nicht aus: Robert Wenner wurde Mitglied, teils auch Präsident, und Ehrenmitglied zahlreicher europäischer Gesellschaften. Um die Schweizerische Gesellschaft für Gynäkologie, deren Präsident und Ehrenmitglied er war, erwarb sich Robert Wenner besondere Verdienste. Er war einer der Initiatoren für die Vereinigung der Société de Gynécologie de la Suisse Romande und der Deutschschweizerischen Gesellschaft für Gynäkologie in eine Schweizerische Gesellschaft.

Nachrufe

62

Den meisten von uns, die mit Robert Wenner freundschaftlich verbunden waren, wird er aber nicht in erster Linie als Wissenschafter oder als gynäkologischer Chefarzt, sondern als Mensch in Erinnerung bleiben. Er war liebenswürdig, verbindlich, mit viel Einfuhlungsver-mögen und „Common sense”, aber doch ein Mann, der wusste, was er wollte, und es kraft seiner natürlichen Autorität auch meistens erreichte. Oft fand er in heiklen Situationen das richtige Wort im richtigen Moment. Robert Wenner war alien Freuden des Lebens zugetan: ein Mensch, der herzlich lachen konnte und in dessen Gesellschaft man sich wohl fúhlte. Obwohl ihn das 
Schicksal mehrmals hart anfasste, hat er seinen Humor nie verloren. Ich selbst habe Robert Wenner fachlich und persönlich viel zu verdanken.

O. Käser 